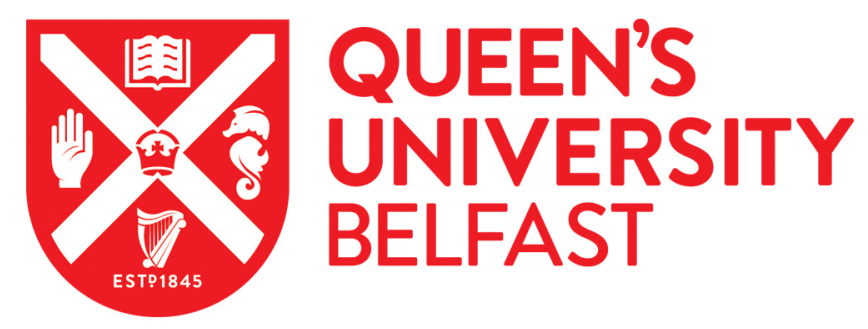

\title{
A Space for Policy Legacy: An Ethnographic Exploration of a Secondary School's Commitment to Creativity after National Policy Priorities Have Changed
}

Moger, P., \& Bagley, C. (2017). A Space for Policy Legacy: An Ethnographic Exploration of a Secondary School's Commitment to Creativity after National Policy Priorities Have Changed. Ethnography and Education, 14, 1-19. https://doi.org/10.1080/17457823.2017.1396544

Published in:

Ethnography and Education

Document Version:

Peer reviewed version

Queen's University Belfast - Research Portal:

Link to publication record in Queen's University Belfast Research Portal

\footnotetext{
Publisher rights

Copyright 2017 Taylor \& Francis. This work is made available online in accordance with the publisher's policies. Please refer to any applicable terms of use of the publisher.
}

\section{General rights}

Copyright for the publications made accessible via the Queen's University Belfast Research Portal is retained by the author(s) and / or other copyright owners and it is a condition of accessing these publications that users recognise and abide by the legal requirements associated with these rights.

Take down policy

The Research Portal is Queen's institutional repository that provides access to Queen's research output. Every effort has been made to ensure that content in the Research Portal does not infringe any person's rights, or applicable UK laws. If you discover content in the Research Portal that you believe breaches copyright or violates any law, please contact openaccess@qub.ac.uk. 
A Space for Policy Legacy: An Ethnographic Exploration of a Secondary School's Commitment to Creativity after National Policy Priorities Have Changed

Pauline Moger and Carl Bagley ${ }^{1}$

School of Education

Durham University

Durham

DH1 1TA

United Kingdom

Corresponding author Pauline Moger-07922381830 pauline.moger@durham.ac.uk

${ }^{1}$ Carl Bagley is in the School of Social Sciences, Education and Social Work at Queens University Belfast 


\title{
A Space for Policy Legacy: An Ethnographic Exploration of a Secondary School's Commitment to Creativity after National Policy Priorities Have Changed
}

\begin{abstract}
To-date qualitative research in the field of policy enactment has tended to focus on investigating existing national policy discourse and the ways in which this discourse is creatively reconstituted in school-based contexts of practice. In this paper the focus is on uncovering the ways in which a schoolbased commitment to a specific policy - in this case creativity - is sustained and has a legacy even after national policy discourse and priorities have changed. By focusing ethnographically upon the legacy of policy at a school-based level, the paper sets out to illuminate the social actions teachers undertake to establish, nurture and protect their institutional and professional investment in and commitment towards creativity.
\end{abstract}

Key Words: Policy enactment: policy discourse: education: legacy: creativity:

\section{Funding}

This paper was supported by a Postgraduate Publication Bursary awarded by the Faculty of Social Sciences and Health, Durham University, UK. 


\section{Introduction}

The concept of policy in academic terms can no longer be perceived as simply the static product of a political system but rather understood as a discursive process, whereby certain principles are brought into practice (Ward et al, 2015); the transition from principle to practice one which is complex and contested involving institutions and individuals in a process of 'creative social action' (Ball, 1998, 270). In terms of the ways in which institutions and individuals respond and interact with policy Ball et al (2012) talk not of policy response but 'policy enactment', which they claim, 'involves creative processes of interpretation and recontextualisation - that is, the translation through reading, writing and talking of text into action and the abstractions of policy ideas into contextualised practices' $(2012,3)$. At a school-based level the enactment process uncovers the ways in which policy is never simply implemented but 'interpreted' and 'translated' in a context of time, space, and place. Braun et al (2010) elaborate on this is the following terms:

...an examination of policy enactment at a school level is about examining connections and inter-dependencies. It is important to consider, firstly, that policies are processes, even when mandated, and policy texts can be differently worked on and with. Secondly, policy practices are specific and contextualised. They are framed by the ethos and history of each school and by the positioning and personalities of the key policy actors involved. And thirdly, and related to the contextualised aspect of practice, policies are mediated by positioned relationships: between government and each local authority, the local authority and each of its schools, and within, as well as between schools.

(Braun et al, 2010, 558)

An important point made by Braun et al (2010) is the notion that relationship dynamics between policy actors engaging with policy processes create shared understandings that act as lenses through which new policies are screened, filtered and dissected for meaning, resonance and relevance. Moreover, and particularly salient in the context of the research presented here, is that "dissonances between embedded institutional values and national policy trends" (Braun et al, 2011, 591) may give rise to site based tensions when policy 
processes are in conflict with the professional context of policy actors, thereby reframing the process of engagement and subsequent policy enactment.

To-date qualitative research in the field of policy enactment has tended to focus on investigating existing national policy discourse and the ways in which this discourse is creatively reconstituted in school-based contexts of practice. In this paper, the focus is on uncovering the ways in which a school-based commitment to a specific policy - in this case creativity - is attempted to be sustained and has a legacy even after national policy discourse and priorities have changed. In focusing ethnographically on the legacy of policy at a school-based level, the paper sets out to illuminate the social actions influential and senior teachers undertake to establish, nurture and protect their institutional and professional investment in and commitment towards creativity. It is acknowledged the study focused upon key departments and staff members pivotal to the overt enactment of creativity in teaching and learning. The opinion and perspective of other staff members however was sought and captured in the form of data 'snapshots' (Pinsky, 2015). This encompassed subject teaching, together with the ethos and value underpinning curriculum delivery. Remarkably and significantly the data snapshots revealed few dissenting voices to the culture of a commitment to creativity in teaching and learning. Data snapshots included observation, informal interviews, informal conversations and discussion with staff members, pupils and parents.

The notion of policy legacy has been used in previous research but this has tended to be in the context of national policy development, conceived as a continuum of policy knowledge to which policy makers seemingly fail to pay sufficient attention (Carabelli and Cedrini, 2010). For the purposes of this paper, the notion of policy legacy is taken to describe and illuminate the nuanced ways in which a school-based policy in this case on creativity is continued to be enacted (Ball et al, 2012) even after national policy priorities have changed. 


\section{The Ethnographic Setting: Enderby School}

A prior professional knowledge of the School on behalf of one of the authors ${ }^{2}$ and its policy commitment to creativity suggested Enderby School to provide a strong case study site for the ethnographic investigation

Enderby School is an educational establishment located in the North Tyneside region of North East of England. The school was opened in the early 1960's in the UK's policy era of tripartite selective education as a County Technical School, co- located on the same site as the existing Grammar School. The School was originally designed for 660 students from the age of eleven to eighteen years and from the outset included provision for sixth form courses. In the late 1960's, with the national policy demise of selective education, the Technical and Grammar School's amalgamated and Enderby High School was created; encompassing both School buildings, the newly established High School offering a 'Comprehensive' education. In 2002, under the Private Finance Initiative (PFI) established by the UK’s Labour Government, a $£ 15$ million scheme was developed for the purpose of creating a 'new build' for Enderby High School. The new build utilised the old site of the High School, with the original Technical School and Grammar School buildings demolished. Staff and pupils were consulted and actively involved in the new school design process. Contemporary architecture melded with the locale's rich Roman Heritage resulted in a building design based abstractly on a Roman Mile Castle. Enderby took possession of the new building in September 2004, providing a comprehensive education for pupils primarily drawn from its immediate locale.

In relation to locale, the school is situated in a mainly white, predominantly working class urban area with a higher than the UK average unemployment rate with home ownership lower than the national average for England. The locale had experienced the economic high and lows associated with the rise and decline of heavy industries, including ship building and coal mining in which many of the local residents had for generations been employed. The school is geographically located in near proximity to

\footnotetext{
${ }^{2}$ The researcher, as Director of Arts for an Arts Centre, had responsibility for overseeing the delivery of a portfolio of cultural programmes in North \& South Tyneside, Enderby was a participant in these programmes.
} 
the River Tyne and was a current site of regeneration with past industries replaced with plans to establish advanced manufacturing in sub-sea and offshore renewable engineering.

In population terms, the school is larger than average for an English secondary school, with 1250 pupils attending. Amongst this school population there is a higher than national average number of pupils eligible for free school meals and those with a Statement of Special Education Needs (SEN) (DfE 2014/15 source material); the overall school population in socio-economic terms can be classed a disadvantaged. In 2013, a school inspection conducted by the government body Ofsted ${ }^{3}$ rated Enderby's educational provision overall as 'Good'.

During the period encompassing the longitudinal research, the Head teacher was supported by seven Assistant Head teachers, with eighty subject specific teachers making up the staff alongside twenty Learning Support Assistants. The Departments ran along the lines of most English secondary schools with one for each curriculum area such as Mathematics, English, Science, Humanities, and Modern Foreign Languages etc. However, the School in addition to the departmental norms, employed three teachers in 'Business and Enterprise', reflecting the schools' specialist status.

Beyond these facts and statistics, when you first view Enderby on approach through the large open main gate with extensive front car park, for staff and visitors, the immediate impression is that of a sweeping modern edifice. On first gaze, the building is not immediately obvious as a school; it could be mistaken for high spec business premises. Entry through the glass vestibule brings the visitor into a huge spacious glass fronted atrium. This space houses the School's reception desk, temporary exhibition space and upper mezzanine seating area. Long silk banners created by pupils adorn the space alongside other pupil generated art work. On the staffed reception desk is a bright contemporary floral arrangement. Small 'comfy' sofa's sit adjacent to the reception desk where visitors are requested to sit, whilst the reception staff deal with alerting staff

\footnotetext{
${ }^{3}$ Ofsted (Office for Standards in Education, Children's Services and Skills) is a government department that inspects and regulates educational institutions. It inspects all English state schools at least once every three years. After the inspection, Ofsted publishes a public report that contains information on the school's performance, its pupils' work, observation reports on lessons and views from staff, parents and pupils.
} 
to the visitors' presence, whilst pupils, staff, and visitors criss-cross the atrium space to access the further reaches of the school. As a result, the visitor is aware of the 'presence' of everyday school life at Enderby. You hear pupils' voices and sense the everyday business of school going on beyond the entrance, but the activity and full volume of 1250 students moving and talking is screened and dispersed by the schools' design. There is a strong sense the students are kept safe and feel safe, with their movements sensibly orchestrated and managed rather than disciplined and herded. Each department has several allocated classroom spaces, some larger than others, with some classrooms leading off central walkways, the walkways themselves used as quiet study areas for pupils working in pairs or small groups; an inner courtyard functioning as the favourite location for pupils to mingle and play during break and lunchtimes. It was these formal and informal settings which were to provide the ethnographic place and space for the study to be undertaken.

\section{The Ethnographic Approach}

A key ethnographic principle adopted in the study can be described as 'a focus upon a discrete setting, concerning the full range of social behaviours, within which the settings complexities can be viewed as displaying 'particular significances'. The approach taken in the research being one of viewing phenomena in everyday context requiring "the direct involvement and long-term engagement of the researcher, recognition that the researcher is the main research instrument and giving high status to the accounts of participants' perspectives and understandings' (Walford, 2009, 26).

Moreover, the research strove to be 'context sensitive, flexible and inner consistent' in determining its epistemological position (Holloway and Todres, 2003); behaviour seen as constructed, not predetermined (Blumer, 1969).

The research process, guided by a symbolic interactionist theoretical framework, was formative and creative with a focus was on the motivations, interpretations and meanings of the actors involved (Hammersley, 1989). The primary research aim was to understand the culture of the school and to capture and penetrate the meanings within that culture as understood by its participants (Woods, 1990). In essence, the research 
design was shaped and influenced by the need to "get close up" to those involved with establishing the space and sustaining the policy legacy of Creativity within the school.

The study collected three kinds of data: national, local and school-based policy texts including school brochures; observational data from lessons, staff meetings, and training sessions; and digitally recorded semi-structured interviews with the head teachers, members of the senior leadership teams, classroom teachers, as well as individuals from external organizations with a direct link to the school in relation to Creativity. Moreover, given the prior association of the school-based researcher with the school, the notion of reflexivity was understood as critical to maintaining the integrity of the research process, requiring close attention being given to its application at each and every level of the research approach (Hammersley, 2002). The use of diary keeping and memo writing provided strong instruments to frame and record thoughts and later distill them in terms of their analytical or reflective relevance in terms of their impact on the research process.

The field work covered the period 2011-2016 with prolonged periods of immersion in the school (circa 120 days) including scrutiny of national, regional and local texts, formal observation of 60 lessons and meetings and 30 taped interviews totalling 55 hours in duration. The research employed a thematic analysis of the data generated (Braun and Clarke, 2006). Data segments, instances and fragments were brought together to create categories defined as having common properties or elements (Coffey and Atkinson, 1996). Iterative cycles of data collection and data analysis were deployed as individual codes were analytically narrowed into conceptual categories and meaningfully organized at a theoretically abstract level of meaning. From the analysis emerged three broad categories under which to reflect on the data in relation to uncovering and understanding the policy legacy of Creativity within the School namely: antecedence and initiation; curriculum embedment; and compromise, constraint and capitulation.

From the thematic analysis (Braun and Clarke, 2006) emerged three overarching categories under which to reflect on the data in relation to uncovering and understanding the policy legacy of Creativity within the School namely: antecedence and initiation; curriculum embedment; and compromise, constraint and capitulation. 


\section{Policy Legacy: Antecedence and Initiation}

In order to fully understand the antecedence and initiation of creativity as it pertained to the social actors involved in Enderby's story, the authors need to speak first more broadly to the notion of creativity and how this was perceived and introduced as a national policy priority. While it is not the intention to provide a chronological or analytical history of creativity within the field of education, it is pertinent to capture the prominence in national policy afforded creativity at a pivotal moment in time, one that played a significant role in terms of the antecedence and initiation of creativity at Enderby.

A key vision for creativity came through the Labour Government Paper Culture and Creativity: The Next Ten Years (DCMS, 2001). Within the document the then Culture Secretary Chris Smith stated that 'In the years ahead, people's creativity will increasingly be the key to a country's cultural identity, to its economic success, and to individuals' well-being and sense of fulfilment'. $(2001,5)$. Prime Minister Tony Blair in the same document affirmed 'This Government knows that culture and creativity matter.... the arts and creativity set us free' $(2001,3)$. Creativity at a national policy level was discursively positioned as politically purposeful alongside innovation, enterprise and design in making a difference to national renewal and economic growth. Bishop (2011) has suggested that the Labour Government's 'unleashing of creativity' in arenas such as education was not designed for the 'authentic realization of human potential' but used instead to 'accelerate the processes of neoliberalism' $(2011,3)$. Whatever the rationale, the political prominence given to creativity threaded through and shaped cultural policy, cascading down to those brokering and influencing how this operated at a regional and local level, including North Tyneside.

Moreover, new opportunities to develop pedagogy and learning through the concept of creativity was presented and to be played out in schools, facilitated through brokered partnerships between educators and cultural sector professionals. To this end in 2002 Labour launched its most significant and well-funded opportunity for such engagement, the flagship programme for schools in England, Creative Partnerships. The idea of the programme was to embed "creative learning" within schools in order to radically 
overhaul teaching methods across all subjects by bringing in visual artists, writers, poets, musicians and the like - dubbed "creative agents" - into schools, to inspire teachers to work in a new way to raise standards, attainment and attendance. Schools such as Enderby were envisaged as becoming free from a restricted curriculum diet with pupils increasingly motivated to learn and engage through their involvement with the Creative Partnerships programme (Hall and Thomson, 2007; Galton, 2009). Enderby's Head teacher Emily described the schools' strategic engagement in the following terms:

We have used national opportunities, local, regional opportunities, to develop partnerships which will help us to enhance what we've set out to do. Creative Partnerships was a key one in that...funding initiatives arrive and funding arrives, and if it's in keeping with our values, with our developments, then we make the most of utilizing that to support us in those developments.

(Emily, Head teacher)

Emily's desire and ability to seek external opportunities reflected a personal and institutional predisposition towards creativity within Enderby, as she described:

Creativity, as part of the school ethos, was something I felt quite strongly about wanting to continue with when I took on headship..... creativity is rooted in the values that we have at Enderby, what we want to achieve for everyone, in our learners and that includes both students and staff, and we want the very best for everyone. We want people to have high aspirations, high expectations, and a real desire to achieve and by being creative, we feel that that will help them on their journey. Creativity is at the heart of what we aim to achieve. We're a very inclusive school. We believe that creativity is really important for everyone, not just in terms of their academic achievement, but in preparation for their wider life, the big wide world when they leave school, along with other skills as well, but creativity being a real focus.

(Emily, Head teacher) 
The picture obtained of Enderby during the study was that of an outward facing value driven school. Creativity was perceived by the Head teacher as purposeful in relation to the education offer provided by the school and accepted as an agenda worth investing in and pursuing. It was in this context that Enderby School was highly receptive to such opportunities as presented by the then Labour Government in terms of its Creative Partnerships programme to progress and develop the existing culture of creativity in teaching and learning. Importantly, in terms of the regional delivery of the programme and its school-based establishment, key stakeholders from both Local Authorities and the Arts Centre responsible for delivering the Arts in Education portfolio successfully lobbied the Arts Council (national) for an alternative delivery model for North \& South Tyneside; one based on increased local determination of priorities and programmes building on existing relationships between schools and arts-based organisations. The 'alternative model' adopted in the locale can be considered as addressing or 'facing up' to 'difficult questions' about the relationship between 'education systems and the emergent social and economic order' (Jones and Thomson, 2008, 724). The study uncovered that Enderby, in apparent collusion with established cultural partners, embraced CP as an opportunity to expand and embed a 'space of hope and practical experiment' as described by Creative Partnerships programme, for creativity within Enderby. As such Enderby and its partners neatly avoided CP becoming yet another 'bounded programme' with schools and their partners unable to integrate funds and inclusion schemes (Hall and Thomson, 2007).

Social actors involved in shaping and delivering Enderby's CP programme appeared well-rehearsed in recognising the juxtaposition between promoting an agenda of inclusivity in the context of addressing social exclusion and the realities of a postindustrial neoliberal society (Jones and Thomson, 2008). English Teacher Anna believed the concept of creativity underpinning teaching and learning at Enderby formed part of the process of addressing and promoting the inclusivity agenda.

The trouble of our catchment area is that kids don't know what is going on around them, they don't know, they've not known anything else other than the immediate locale or Newcastle at times and they don't see the bigger picture so having creativity and everything that underpins that at Enderby, 
that's exposing the wider world to them even more. I think that can have a massive impact. (Anna, English teacher)

It was recognised however that communities in North Tyneside struggled to reach the ambition to 'have it all' through education reform instigated and imagined in the 1960's and 1970's, equalising opportunities for social mobility and a 'good life' (Jones and Thomson, 2008, 724). Nonetheless, delivery of an 'alternative' CP model was perceived as a potential sustainable vehicle for 'creativity' with a 'built in' legacy addressing the continuing local struggle for economic well-being.

Humanities teacher Tom spoke of creativity at Enderby as being a 'crucial part' of the well-being agenda.

We think about every child matters and we think about the economic wellbeing of our students. Well, I guess creativity for me links a lot into that at Enderby; for students to achieve economic wellbeing, creativity is quite crucial.

(Tom, Humanities teacher)

Teaching staff at Enderby such as Tom, played a key role in delivering the 'alternative' creative partnership agenda. Projects subsequently delivered stemmed from what the School perceived it needed; teachers working collaboratively with artists to try and deliver a more creative curriculum. Not all was 'plain sailing' as Assistant Head teacher Lucy commented.

At the very start of CP it wasn't always a smooth journey; there was some resistance from some staff who didn't feel it was necessary to explore their own teaching practice. People assumed they understood creativity or that it was something directly related to arts subjects in the curriculum so our initial focus was on staff development. We also recognised that although creativity might occur naturally, it can also be developed and improved through working with artists. We were all coming from different experiences, and people have different starting points, and different understandings of how people operated, and it took a long time for us to learn how artists really 
work, and how arts organizations and different experts from outside think, and we had to also get over the arrogance of being school teachers who thought we knew everything and have nothing to learn.

(Lucy, Assistant Head teacher)

In line with the findings of Bragg and Manchester (2011), Enderby's teachers' capacity to engage was enhanced through long-term partnerships and relationships with creative practitioners. The reported experiences of the School's Science Department are particularly noteworthy:

Our practice in science has been revolutionised, I didn't think that I would see science being taught through dance, a drama lesson being used to teach science - moving around and being electrons, rather than just looking at a diagram of an electron in a book. Pupils have used sculpture to investigate how the body works to help understand biology.

(Extract, Creative Partnerships 2011 Audit Report)

In addition to developments within Science one of the most salient features of creativity development at Enderby was the creation of a cross curricular learning framework. The School utilised the professional development opportunities offered through the CP programme to enable staff to work with external partners to explore those challenges, think about conceptual teaching and how staff might approach embedding creativity. As a direct result, a cross-curricular learning framework emerged called the 'Magnificent 7'. The framework, adopted across school, reinforced the notion of creativity alongside 6 others, as a key transferable learning skill to be practically applied by teachers as a 'tool' to support learning in all subjects. Maths teacher Fred spoke of embedding enactment across school through the vehicle of in-service teacher training.

We have the notion of the Magnificent 7 strand, which we try and build into our teaching at every stage.... it's something that we've done a lot of in service training on and it's something that we've been encouraged to do.

(Fred, Maths teacher) 
English teacher Anna reiterated the totality of 'creativity' as a known encompassing term across school.

Creativity is supposed to be at the heart of every single subject and every single teaching member staff and for the students themselves. It's been really pushed in terms of a Magnificent 7 Skill as an underpin.

(Anna, English teacher)

It is interesting to note the use of the words 'supposed' by Anna and 'pushed'. Use of such terms might lead the reader to question how far the rhetoric was 'believed' and acted upon, in comparison to simply repeated as a mantra. The longitudinal study sought to discover and reveal policy legacy. Through observation, diary notes, formal and informal interviews, conversations and simply 'hanging around' the school, evidence suggested a space for legacy was found and creativity 'believed in'. The notion of creativity as an underpinning ethos and 'at the heart' of teaching and learning for the whole school community was understood by individuals. This was articulated in their everyday language and visually broadcast in written material emanating from the school during the period of the research. This included material pinned to walls in classrooms, the schools' website, school brochure, newsletters and media coverage of school activity. As an illustration, when entering the school premises and foyer area it was apparent this outward facing public arena was used as an exhibition space as well as housing 'reception'. Two 'roller banners' straddled the foyer literally 'in your face' as a visitor to Enderby, proclaiming the success of the school and Ofsted commentary. The banners linked exam results and achievement with creative teaching and creativity as a school 'value'.

Whilst the generic creativity 'message' appeared shared, a further significant feature of curriculum experimentation involved a specific group of teaching staff at Enderby, the self-styled the 'Creative Arts' team. The team, encompassing teachers in music, visual arts and drama, experimented with their personal pedagogy and notion of student led learning. They brought together single art subjects to create a hybrid curriculum subject which they branded 'Creative Arts' and offered pupils the opportunity to engage in thematic projects. 
The existence of Creative Arts as a hybrid curriculum subject alongside the development of a cross curricular framework profiling creativity and informing the Schools sustained commitment to Creative Partnerships, aligned with and helped augment an existing culture and ethos at Enderby; a culture in which professional commitment to the value of creativity was the accepted norm. In effect Creativity was principally what Enderby 'wanted', pursued and was accepting of, primarily because Creativity spoke to the personal agendas of individuals and the common purpose of school achievement. Creativity was, in essence, a recognised and accepted part of everyday life of the school.

\section{Policy Legacy: Curriculum Embedment}

The move from Labour to Coalition Governments evidenced and witnessed the demise of Creative Partnerships and with it the educational policy commitment to creativity at national level. Nevertheless and notwithstanding these changes Enderby continued its commitment to creativity and following a school-wide review of its provision involving both staff and students decided to develop and embed a bespoke creativity curriculum strand which would replace 'Creative Arts' on the school timetable, led and delivered by the Creative Arts team within the school. As the Head teacher observed:

We are adding creativity to our curriculum at a time when most schools are going through deficit cuts, budgets, funding cuts, and they're having to take arts and things off the curriculum.

(Emily, Head teacher)

The School's first steps involved delivery of pilot 'Creativity' lessons in Years 7, 8 and 9, introduced into the timetable for the autumn school term 2011. In addition, the School drew on local authority support and secured 'expert' external guidance to assist the School in devising and shaping the content of a bespoke creativity curriculum strand. The approved strand was finally rolled out in 2013. All members of the Creative Arts team were involved in teaching the subject including Music teacher Jim, Visual Arts teachers Lottie and Diane, Assistant Head Teacher Lucy (as a music teacher) and Drama teacher Lynda. The strand was timetabled as one lesson per week for each Year group lasting fifty minutes. 
The School's first steps involved delivery of pilot 'Creativity' lessons in Years 7, 8 and 9, introduced into the timetable for the autumn school term 2011. In addition, the School drew on local authority support and secured 'expert' external guidance to assist the School in devising and shaping the content of a bespoke creativity curriculum strand. The approved strand was finally rolled out initially to Years 7,8 and 9 in 2013. All members of the Creative Arts team were involved in teaching the subject including Music teacher Jim, Visual Arts teachers Lottie and Diane, Assistant Head Teacher Lucy (as a music teacher) and Drama teacher Lynda. The strand was timetabled as one lesson per week for each Year group lasting fifty minutes.

The creativity lesson did not displace single art form teaching of Visual Art, Music and Drama. The new strand emerged from staff and pupils review of the Creative Arts curriculum strand. Jones and Thompson (2008) suggest that Creative Partnerships simultaneously ran with the 'hare of teacher autonomy and resurgent progressivism' whilst 'hunting with the hounds of management driven change' (2008, 725). Arguably the new bespoke curriculum stand was a perfect example of what Jones and Thompson (2008) describe as 'rhetorical doubleness' and 'necessary tactic'. Enderby created a space for policy legacy post CP as both hare and hound.

The following narrative highlights and profiles opinion drawn from pupils closely observed within the delivery of the strand and new learning environment, teaching staff and a key long standing cultural partner of the school.

Creativity as a bespoke curriculum strand encompassed teachers and students cocreating learning, where both pupils and teachers were able to 'be themselves'. Pupils' Ella, and Lizzie, aged eleven and twelve years old were members of Jim's Year 7 creativity class at Enderby. They described how creativity was 'not like' other lessons:

So it's not like other lessons and we find it more interesting and Mr Smith just tells, like he doesn't really give us rules. It's more just like you can't ask 'Can I?' questions, and get on with it and do whatever you want, so Mr Smith doesn't really give a limit of what we can do. Because in other subjects you get one thing to do and you have to do that, but he just lets us, we could 
whatever we want. Like we could turn the tables upside down if we wanted and Mr Smith doesn't mind, but like in other classes you wouldn't be allowed to do that.

(Ella, Year 7)

With our creativity lesson it's not question after question, it's not like writing down in books; but with creativity it's quite free, if you know what I mean. It's more enjoyable than sitting at a desk all the time and you're doing different stuff, like moving tables...we did a puppet show and we got to move all the tables and things and different things. Whereas other lessons I don't think we really get the choice to do like we do in creativity. I think it's more, well, for instance, it's called creativity and creative means to think of new things, and you're not going to really achieve anything if you just sit at a desk and just write, but if you do things in your own way, then I think it will be easier for you to learn.

(Lizzie, Year 7)

Visual Arts teacher Lottie spoke of the 'classroom climate' she created and the freedom she believed this provided for herself as teacher and her pupils across year groups.

What's been really nice about the creativity lessons I've taught to Years 7, 8 and 9 is that I certainly feel more in charge of what's going on. And I don't mean that in a traditional teacher way of sort of standing up front, dictating what happens, but I mean I've been able to get much more out of that lesson in terms of me as a person than possibly my art teaching, because there's that freedom to go off on a tangent and to try things out. I feel more open to the possibilities of the subject and seeing what actual impact it can have on individuals, how it can change people, and that sounds a bit obvious actually, but it can change people, it can make people, you can see them develop, and blossom, and flower, and be really proud of what they do, and yeah that does happen in other subjects, I understand that, but I think creativity as a lesson does allow people to really invest something of themselves in the work if it's handled well.

(Lottie, Visual Arts teacher) 
Within such environments students were encouraged to be open to experience, develop an ability to toy with ideas and self-assess, characteristics associated with the' inner state' of a creative person (Lewis, 1971). The bespoke creativity curriculum epitomized the ways in which teachers at Enderby believed it was possible and purposeful to enact creativity as part of a core educational offer, establishing a 'normalised' presence for creativity within the school. For the School, this was effectively 'nailing' creativity onto the mast of 'subject' teaching and student learning; embedding a knowledge-base of creativity into the heart of the School.

Importantly pupils were encouraged to adopt and understand Enderby's' shared language of creativity. This was an influential social action and the bespoke lesson was a focused vehicle and controlled environment within which language could be embraced and collectively repeated, normalising associations and links between creativity and the mantra of skills, required attributes and the like. Music teacher Jim spoke of this taking place.

From the students' perspective for some of the phrases that we hear them using, and some of the language we hear them using, it's becoming a shared language. We can see that the shared language of creativity, that we worked hard to get to, is now being used more and more often by the students and understood by them.

(Jim, Music teacher)

Some data collected from pupils did however reveal Enderbys' students' perception of creativity per say was somewhat eclectic. Not all pupils colluded with Enderbys' belief that creativity was valued and valuable in teaching and learning. Some pupils expressed the belief that creativity was an inherent human trait, and could not be taught. Others thought creativity was too 'fussed over' and over emphasised in school. Dialogue and conversation relating to creativity and employability was the exception to this range of opinion. Certainty and positivity reflected in the language pupils used and a direct correlation could be made between the adults' rhetoric heard in the classroom and opinions expressed by pupils on the value of creativity in 'getting a good job'. Brown (2003) spoke of educational establishments colluding with the rhetoric of 'learning is 
earning' and pupils reflected this notion in phrases such as 'new skills mean more money' and 'lots of well paid jobs involve creativity'. Pupils appeared to be highly influenced by teachers' overt contextualisation of creativity at Enderby in relation to skills development and acquisition of attributes required for employment. Pupils colluded with their teachers and universally repeated the mantra that creative minds and creative people were 'wanted' by employers. Opinions such as 'bosses will want someone creative working for them' and jobs often ask for new ways of doing things and creativity can help with that' were expressed. Creativity was perceived by pupils as being an 'advantage' to them in preparation for employment, echoing the adults' beliefs.

A key cultural partner of the school, Arts Centre Officer Jill, spoke of Enderby as being a risk-taking forerunner in creativity and the role creativity played in preparing your people for perceived 'new jobs'.

They're basically the forerunners in creativity and developing a curriculum strand is a great way of delivering across different art form areas, particularly at a time when the arts is being hit.... I think that that can be a misconception from other people looking in at the school who don't know where they're going with creativity, how they've developed it, and where they've come from. I think it's more manageable doing it as a creativity curriculum strand, because it generally does fit more with those areas to start off with and then you can build from it and move it forward. Students in Enderby, the opportunities that they've been given... I would love to see how many of them develop a job that doesn't currently exist, and I think creativity is a major player in that and I think the school are giving them an excellent grounding to be able to develop that, have the confidence to take those risks, and try new things that haven't been done before.

(Jill, Arts Centre Officer)

This 'all-encompassing position', which we reveal in the next section, was to face serious challenge as neo-liberal educational policy discourses at national level hardened. 


\section{Policy Legacy: Compromise, Constraint and Capitulation}

As Coalition government education policy sought to strengthen the political project of neo-liberalism around notions of performativity (Ball, 2012) and accountability (O’Neill, 2013) so creativity already highly marginalised, in national policy discourse risked being further undermined and placed in jeopardy at school-based level (Bates, 2012; Forrester, 2011). In such a climate Head teacher Emily believed she had a direct role to play in safeguarding creativity from policy change. She commented:

If I'm honest, the national agenda could possibly, if allowed, stifle creativity, because we have so many directives now...but myself I see my role as the gate keeper. Yes, we will follow the national agenda and meet expectations, but we won't ever lose sight of what's really important to us in terms of the school that we believe in and are important for us on a daily basis.

(Emily, Head teacher)

The 'hare' (Jones and Thompson, 2008, 724) of teacher autonomy enjoyed by the Creative Arts team began to feel the heat of the hounds, as Visual Arts teacher Diane described.

We're very lucky at the moment, even though we have to report on it, we don't technically have to assess it to any government standard or any school standard. It's very much quite loose and I think that's quite nice that you know, that you can still do that. How long that will last, I don't know, because you just don't know how anything's going at the moment. It will be interesting to see what happens with the timetable once the new imposed Key Stage 3 curriculum comes into play and then, obviously, the new GCSEs (E-Bacc) and whatever else changes Gove decides we're having, but who knows?

(Diane, Visual Arts teacher)

Despite the desire on behalf of staff to sustain the legacy of creativity within the school a strategic compromise needed to be reached, as Diane predicted, between accommodating the national government demands of the New National Curriculum to 
Key stage 3 teaching and maintaining a commitment to the presence of creativity as part of the School's curriculum. Because of this decision, senior staff continually appraised any new government initiative that might provide an opportunity to support or enhance the school's creativity agenda. One such opportunity was perceived in relation to teaching the new subject of Computer Science, the School considering the ways in which Creativity, Business \& Enterprise and ICT might come together under one 'connected umbrella' subject. Strategically, morphing and manipulating imposed curriculum development offered teachers the potential for developing a unique teaching framework, labelled project 360 degree, which, as Assistant Head Teacher Lucy succinctly stated, 'nimbly' safeguarded non-core subjects such as creativity.

Linking Creativity with IT and Business \& Enterprise at Enderby created a 'triangle' of subjects, an action that could be considered as a strategic mechanism for scaffolding sustainability. Project 360 degrees demonstrated the key actors' tenacity in 'managing' policy to further the schools rather than Government's ambitions and endorse a creativity-informed vision for teaching and learning.

However, Enderbys' capacity to be fluid and artful in response to national policy directives came under further pressure in Spring 2014 in terms of funding priorities. Senior leaders at Enderby in the face of further budget restrictions considered the balance between funding core and non-core subjects. Assistant Head Teacher Lucy spoke of a 'crossroads' being reached as project 360 degrees came under scrutiny.

We saw changes to the key stage 3 curriculum as such a positive opportunity to advance our ambitions and this was understood by staff in the creative arts team as our ongoing legacy of creativity and we strove to avoid hiatus and embed creativity... but Enderby' faces a more pressing internal dilemma in the direction and scope of the new model. Questions are being asked about the high level of costs involved in staffing for creativity and enterprise teaching as non-national curriculum based subjects. In the 'bigger picture' of our school funding priorities we have been challenged. Avoiding teacher redundancy has become a focus of the senior leadership's team's attention, so a crossroads has been reached.

(Lucy, Assistant Head teacher) 
Enderby's strategic solution to this challenge was to find a further window of opportunity to accommodate the 360 degree project and sustain creativity through the initiative REAL (Rigorous Engaging Authentic Learning) programme. REAL was set up as a partnership programme between the UK's Innovations Unit and High Tec High in the US, to promote an approach to learning through projects in schools. Projects incorporate a design for learning that connects deep subject content with real life problem solving. In September 2014 Enderby introduced the programme into the curriculum with three consecutive or 'back to back' 'REAL' project based creativityinformed lessons for Years 7 and 8 The Assistant Head teacher Lucy subsequently described the School's engagement with REAL in the following terms:

Participation in the REAL programme is opportunist and has provided financial support, gravitas, and protected teaching jobs and time in the curriculum, but we face a massive risk of losing something else. We feel that staff are tightrope walking the legacy of creativity and we might just lose our balance and fall.

(Lucy, Assistant Head teacher)

At the time of the final fieldwork interview in April 2015 the perception of senior staff associated with Enderby's commitment to the inculcation of creativity into the School curriculum, remained optimistic that staff and pupils as authentic co-creators of the REAL programme, meant that the notion of creativity whilst distilled remained embedded in the ideology of REAL and the School. As Music teacher Jim observed:

We are manipulating REAL in terms of a new language of learning, we want our pupils to know about being in the world and their place in the world and understand that they have a view and can think and appraise. We are moving away from a 'tell me what to do' culture in teaching and learning so selfexpression is encouraged and creativity is still valued. I think pupils are achieving creative outcomes through project working as well as engaging in creative thinking. One of my seven pupils critiqued a Year Twelve BTEC performing arts performance under my observation recently. The BTEC students said the year seven's feedback was really valuable and of good 
quality. I honestly believe the umbrella the Creative Arts team spoke about in the past of about pupils leading their own creative learning, exploring through asking essential questions and product creation is now being realised. This all vindicates, validates and celebrates where we were five years ago.

(Jim, Music teacher)

Compromise and conformity was considered to safeguard continued commitment and moving those involved toward fresh interpretations of creativity in teaching and learning. Jim's apparent optimism could be taken as reflecting the continuum of provision of creativity at Enderby. For others, such as the Assistant Head teacher Lucy, creativity's incorporation within REAL had changed markedly in profile and content from the way in which it was perceived and conceived at the time of the School's initial engagement with Creative Partnerships.

In September 2015, a process of leadership succession was underway at Enderby. Retiring Head Teacher Emily worked alongside the newly appointed Head Teacher Alan to 'hand over' leadership of the school. Emily shadowed Alan in his role over a whole school year, leaving the school permanently in July 2016. Lucy remained in her role as Assistant Head Teacher but made a decision to negotiate early exit from teaching, choosing to also leave the school in July 2016 rather than her planned retirement in July 2017. Lucy was asked about the impact a change of leader, and subsequent staff restructuring at Enderby had made in relation to the policy legacy of creativity at the School:

Our focus has shifted, the distributed leadership ethos has changed and we are now geared towards raising standards and preparing for Ofsted inspection. It's less strategic leadership team and more functional management team, our role akin to advanced skills teachers with outstanding practice.... Our brand or identity has changed, I was told creativity was not helpful, so it's no longer there and we look more corporate. We no longer have a Creative Arts team, just single art form subjects and there are plans to link Drama with English and Visual Art with Technology. Teaching and learning is subject specific with no cross curricular working and there is 
pressure on staff to show pupil progress so evidencing learning is restricted to work books and marking. Staff members from the former Creative Arts team are no longer part of the team delivering REAL. Creativity has gone from the triangle; it's now just IT and Business skills. In the bigger political picture we are being squeezed so it's a case of survival at Enderby not empowerment. I consider Alan one of the new breed of young Heads, his belief and vision is very different to what we shared under Emily but that's just how it is.

(Lucy, Assistant Head teacher)

Creativity in the specific domain of Enderbys' curriculum and visible presence within the school appeared to have been undermined and lost; the victim of a change in leadership and a culture of schooling in which national policy discourses around performativity and accountability had seemingly come to subsume and predominate.

\section{Conclusion}

In this paper, the aim has been to uncover one schools journey in its policy enactment of creativity; a process of enactment which continued at school-based level even after national governmental commitment and policy discourses on creativity had ceased and which we therefore termed policy legacy. In adopting an ethnographic approach, the research sought to understand and portray the reasons for the School's commitment and the strategies for policy enactment it adopted and confronted in the context of their situated reality (Ball et al, 2012).

The research reveals the somewhat serendipitous and situated way in which initially national and regional policy commitments to creativity such as Creative Partnerships were politically available, welcomed and institutional mediated into the curriculum of the School. The crucial point here, as made by Ball (1994), is that 'policies do not normally tell you what to do, they create circumstances in which the range of options available in deciding what to do are narrowed or changed, or particular goals or outcomes are set' $(1994,9)$. In this way the Head teacher, Assistant Head teacher and other teachers professionally predisposed to the value of creativity used Creative Partnerships as a springboard for policy enactment within the School. From this 
perspective, they positioned themselves as 'key actors, rather than merely as subjects in the policy process' (Braun et al., 2010, 549).

In the case of Enderby and creativity, it would appear the values and commitments of a particular school leader or leadership team and the profile of the particular policy as well as its timing, contribute markedly to the attitude, stance and engagement of teachers towards the policy enactment of creativity within the School (Maquire et al 2015). As Maquire et al (2015) observe, 'enacting policy is a complicated and sometimes inchoate process. It is both contingent and specific, situated in time/space and seen as less/more important by different policy actors in schools' $(2015,7)$.

For the 'policy actors' at Enderby there existed a passionate professional commitment towards creativity and it was this commitment and shared vision by teachers within the school which led to the attempt to further embed creativity within the School's curriculum; a move which was counterintuitive to national governmental policy discourses which were moving strongly away from creativity and schooling. Ranson (1995) highlights the purpose of policy for governments to 'codify and publicise the values which are to inform future practice and thus encapsulate prescriptions for reform' $(1995,440)$. National governments education policy discursively sets out to dictate, control and gain authority over the nature, purpose and practice of education. This includes which issues it will support and prioritise and which ones it will ignore and neglect.

In this regard Ball (2008) identifies 'a generic global policy ensemble that rests on a set of basic and common policy technologies [...] marketisation, managerialism and performativity and [...] the increasing colonisation of education policy by economic policy imperatives' $(2008,38)$. For Enderby, the power and influence of these increasing 'colonising' pressures on the school was clearly evident as, at a national level, governments moved at first to Conservative Coalition and then Conservative. In such a political climate with ever increasing demands on standards and accountability and changes to the National Curriculum it became increasingly difficult for the School to hold on to its policy commitment to creativity. 
Strategically the School attempted to safeguard the policy through integration and incorporation within new technologies and new ways of doing, ultimately however the power of national policy discourses placing new demands and expectations on the School for them to prioritise, render and recontextualise proved too great. Moreover, the key policy actors and advocates in the School for creativity chose to retire or move on, leaving a new Head teacher in charge committed to embracing the new policy technologies.

Borrowing from Ball et al (2012) we tentatively offer a diagram (figure 1) as a visual 'thinking map' of our thinking about policy legacy $(2012,144)$

[Figure 1 here]

Like Ball et al's, (2012) the 'thinking map' is deliberately unfixed and messy in order to reflect the nuanced, complex and interweaving key factors in the School's journey as captured and uncovered through the ethnographic research. Policy is not being 'done to' the school as crucial elements and factors move and interact, supporting and enabling Enderby to enact and embed creativity and to provide - albeit limited - a legacy for it within the School. Ball et al (2012) talk of policy enactment as a process of interpretation and the bringing of 'policy ideas into contextualised practices' $(2012,3)$.

We would contend that our ethnographic research in attempting to uncover the policy enactment and legacy of creativity in the case of Enderby highlighted three major factors, all of which align with the findings of Maguire et al (2015). Firstly, the centrality and significance of key policy actors in both initiating and embedding the policy within the school and making strategic attempts to sustain the policy against the pressure of an increasingly counter-cultural national policy discourse of performativity. The importance of these key policy actors is further evidenced by the way in which their departure from the School seemingly contributed to the end of the School's commitment to creativity. Secondly, the data highlighted the power of national governmental policy discourse; discourse which when in support of school-based policies on creativity helped to support and frame the School's policy and discourse when not in support and reconfigured contributed markedly to the demise of creativity within the School. 
Thirdly, the ethnographic approach of prolonged immersion in the School was able to capture the temporal nature of policy enactment and legacy. The ways in which over a period of 5 years the School evolved and moved in its policy on creativity, from one in which it was institutionally at the heart of the School to one in which its legacy came to reside quite possibly only in the heart of those key policy actors who have since left the School. To this end we give the final word to Enderby's former Music teacher Jim, 'the legacy of creativity for me is 'me' if that doesn't sound too daft, and you know what that's really exciting'.

\section{References}

Ball, S. J. 1998. "Big Policies/Small World: An Introduction to International Perspectives in Education Policy”. Comparative Education, 34(2): 119-130.

Ball, S. J. 2008. The Education Debate: Policy and Politics in the Twenty-First Century. Policy Press, Bristol

Ball, S. J. 2012. Global Education inc. : New Policy Networks and the Neo-Liberal Imaginary London; New York: Routledge.

Ball, S. J., Maguire, M and Braun, A. 2012. How schools do policy: Policy enactments in secondary schools: Routledge.

Bates, A. 2012. "Transformation, trust and the'importance of teaching': continuities and discontinuities in the Coalition government's discourse of education reform". London Review of Education, 10(1): 89-100.

Bishop, C. 2011. "Con-Demmed to the Bleakest of Futures: Report from the UK". eflux Journal (22).

Blair, T. 2001. Foreword by the Prime Minister In: Culture and Creativity: The Next Ten Years. London: Department for Culture, Media \& Sport.

Blumer, H. 1969. Symbolic Interactionism: Perspective and Method: Englewood Cliffs Prentice-Hall.

Bragg, S. and Manchester, H. 2011. Creativity, School Ethos and the Creative Partnerships Programme: London: Creativity, Culture and Education.

Braun, A., Ball, S.J., Maguire, M. and Hoskins, K., 2011. "Taking context seriously: Towards explaining policy enactments in the secondary school". Discourse: Studies in the cultural politics of education, 32(4): 585-596. 
Braun, A., Maguire, M., and Ball, S. J. 2010. "Policy enactments in the UK secondary school: examining policy, practice and school positioning”. Journal of Education Policy, 25(4): 547-560. doi: 10.1080/02680931003698544

Braun, V., and Clarke, V. 2006. "Using thematic analysis in psychology”. Qualitative Research in Psychology, 3(2): 77-101. doi: 10.1191/1478088706qp063oa

Brewer, J. D. 2000. Ethnography Buckingham: Open University Press

Brown, P. 2003. "The opportunity trap: education and employment in a global economy”. European Educational Research Journal, 2(1): 141-179.

Carabelli, A., and Cedrini, M. 2010. "Global imbalances, monetary disorder, and shrinking policy space: Keynes's legacy for our troubled world”. Intervention. European journal of economics and economic policies, 7(2): 303-323..

Coffey, A., and Atkinson, P. 1996. Making sense of qualitative data : complementary research strategies Thousand Oaks: Sage Publications.

Forrester, G. 2011. "Performance management in education: milestone or millstone?" Management in Education, 25(1): 5-9. doi: 10.1177/0892020610383902

Galton, M. 2009. "Going with the flow or back to normal? The impact of creative practitioners in schools and classrooms". Research Papers in Education, 25(4): 355-375. doi: 10.1080/02671520903082429

Hall, C., and Thomson, P. 2007. "Creative Partnerships? Cultural Policy and Inclusive Arts Practice in One Primary School". British Educational Research Journal, 33(3): 315-329. doi: 10.2307/30032613

Hammersley, M. 1989. The dilemma of qualitative method : Herbert Blumer and the Chicago Tradition. London: Routledge.

Hammersley, M. 2002. Educational Research, Policymaking and Practice London: Paul Chapman Publishing.

Holloway, I., and Todres, L. 2003. "The Status of Method: Flexibility, Consistency and Coherence". Qualitative Research, 3(3).

Jones, K., and Thomson, P. 2008. "Policy rhetoric and the renovation of English schooling: the case of Creative Partnerships". Journal of Education Policy, 23(6): 715-727.

Lewis, H.P. 1971. "What Research Says to the Teacher About Developing Creativity". Art Education, 24(5): 32-35. 
Maguire, M., Braun, A., and Ball, S. 2015. "Where you stand depends on where you sit': the social construction of policy enactments in the (English) secondary school”. Discourse: Studies in the Cultural Politics of Education, 36(4): 485499.

O’Neill, O. 2013. "Intelligent accountability in education”. Oxford Review of Education, 39(1): 4-16.

Pinsky, D. 2015. "The sustained snapshot: Incidental ethnographic encounters in qualitative interview studies". Qualitative Research, 15(3): 281-295.

Ranson, S. 1995. “Theorising education policy”. Journal of Education Policy, 10(4): 427-448.

Walford, G. 2009. "For ethnography”. Ethnography and Education, 4(3): 271-282. doi: $10.1080 / 17457820903170093$

Ward, S., Bagley, C., Lumby, J., Hamilton, T., Woods, P., and Roberts, A. 2016. "What is 'policy'and what is 'policy response'? An illustrative study of the implementation of the Leadership Standards for Social Justice in Scotland". Educational Management Administration \& Leadership, 44(1): 43-56

Woods, P. 1990. Symbolic Interactionism : Theory and Method. [Milton Keynes]: The Author. 